\title{
Preliminary Studies on Anticoagulation and Antiplatelet Activities of Plinia cauliflora (Mart.) Kausel Leaves Extract
}

\author{
Filipe Tanelli¹, Thaís Gascón Belardo², Carlos Henrique Foncesca Peiro², Robson Miranda da Gama ${ }^{1 *}$, \\ Fernando Luiz Affonso Fonseca ${ }^{2}$, José Armando-Junior ${ }^{1}$ \\ ${ }^{1}$ Laboratório de Pesquisa do Curso de Farmácia. Faculdade de Medicina do ABC, Santo André, SP, Brazil. \\ ${ }^{2}$ Laboratório de Análises Clínicas. Faculdade de Medicina do ABC, Santo André, SP, Brazil.
}

\begin{tabular}{l} 
ARTICLE INFO \\
\hline Article history: \\
Received on: 22/08/2016 \\
Accepted on: 28/12/2016 \\
Available online: $30 / 04 / 2017$ \\
\hline Key words: \\
Anticoagulant activity; \\
hemostasis; Plinia cauliflora \\
(DC.) Kausel; platelet.
\end{tabular}

\section{INTRODUCTION}

According to World Health Organization (2015) an estimated 17.5 million people died from cardiovascular diseases (CVDs) in 2012, representing $31 \%$ of all global deaths. Of these deaths, an estimated 7.4 million were due to coronary heart disease and 6.7 million were because of stroke. People with CVDs or who are at high cardiovascular risk (since to the presence of one or more risk factors such as hypertension, diabetes, hyperlipidaemia or already established disease) need early detection and management using counselling and medicines, as appropriate. CVDs are a group of disorders of the heart and blood vessels and they include many diseases such as coronary heart; cerebrovascular, peripheral arterial, rheumatic heart, congenital heart and deep vein thrombosis and pulmonary

* Corresponding Author

Email: robson.gama@fmabc.br embolism (WHO, 2015). Disturbances in physiological process on hemostasis lead to blood flux regulation alteration and an intense activation of coagulant factors that result either in hemorrhage or thrombosis (Versteeg et al., 2013). Without hemostasis, an abnormal formation of fibrin could result in the occlusion of the blood vessel (Ostrowski et al., 2014) causing disturbances mentioned above. Coagulation is initiated by extrinsic tenase, which forms when factor VIIa binds to tissue factor. Extrinsic tenase activates factors IX and X and in the presence of calcium, which is mobilized into the cytosol, is mediated by the activation of phospholipases, also the levels of $\mathrm{Ca}^{2+}$ in human platelets activation is directly downregulated by cAMP, which is affected by prostacyclin produced in endothelian cells. The factor IXa binds to negatively charged phospholipid surfaces, where it interacts with factor VIIIa to form intrinsic tenase, a complex that efficiently activates factor $\mathrm{X}$. Factor $\mathrm{Xa}$ binds to factor $\mathrm{Va}$ on negatively charged phospholipid surfaces to form prothrombinase, 
the complex that activates prothrombin to thrombin. When platelet GPIIb/IIIa receptors are inhibited, thrombin then converts fibrinogen to fibrin. Activated platelets or monocytes provide negatively charged phospholipid surfaces on which these clotting reactions occur (Fuentes and Palomo, 2014; Bates and Weitz, 2005). When hemostasis fails, leading to blood coagulation that could cause a vessel occlusion, the use of anti-coagulant drugs could be crucial; currently the medical options are unfractionated heparin (UFH), coumarin, low molecular weight heparin (LMWH), and the most recent drug introduced in the market - the synthetic pentasaccharide fondaparinux (Aguirre and Borgeat, 2013). Although all the anti-coagulants mentioned above are effective, they present some restrictions to their use, and the need of special care due to hemorrhagic risk and limitation in the administration; for the same reasons, some are used under a rigorous control (Aguirre and Borgeat, 2013). Several investigations are under way, aimed at developing new, safer, and more effective anti-coagulant drugs, with less hemorrhagic risk and fewer side effects or interaction with drugs and food (Poulsen et al., 2012). In addition, these new drugs should be easy to be administrated by medical staff, dispensing the need of additional laboratorial exams to control blood coagulation (Aguirre and Borgeat, 2013). Medicinal plants are natural resources, yielding valuable herbal products which are often used in the treatment of various ailments. Many studies have been conducted to discover new natural products with coagulant or anti-coagulant/antiplatelet properties that could be more efficient and present a safer alternative to synthetic drugs (O'Leary et al., 2004; Bojić et al., I2011; Mahajan and More, 2012).

Plinia cauliflora (DC.) Kausel is a plant from Myrtaceae family, which has one hundred twenty nine genders. This specie, a native Brazilian rainforest plant, has demonstrated great therapeutic activities, such as: antioxidant and antimicrobial (Souza-Moreira et al., 2010) and antidiarrheal (Souza-Moreira et al., 2011), these activities are due to the presence of flavonoids and tannins. O'Leary et al. (2004) suggest a positive effect using flavonoids in cardiovascular diseases and have shown that some flavones can act as antiplatelets. The objective this study was evaluated the effect of aqueous extracts of Plinia cauliflora (DC.) Kausel leaves in different concentrations, on the hemostasis through changes in platelet aggregation and blood coagulation.

\section{MATERIAL AND METHODS}

\section{Plant material}

Plinia cauliflora (DC.) Kausel was cultivated at Faculdade de Medicina do ABC'S Medicinal Herb Garden; leaves were manually collected and dried at $50^{\circ} \mathrm{C}$ (in a hot dry air chamber) for a week prior, to storing at $20^{\circ} \mathrm{C}$ under controlled conditions of humidity and light.

\section{Phytochemical Screening}

These tests were performed by using dried leaves powder of Plinia cauliflora (DC.) Kausel to evaluate plant secondary metabolites (total phenols; tannins; flavonoids; alkaloids and saponins) utilizing standard methodologies described by Trease and Evans (1989) and Harborne (1998).

\section{Extracts preparation}

The leaves were grinded to powder using a mill (Marconi ${ }^{\mathrm{TM}}$ MA 048) and left stirring in ethanol $100 \%$ for $24 \mathrm{~h}$, followed by filtration through a Buchner funnel. The ethanolic filtrate was evaporated to dryness by means of a rotary evaporator (Fisatom $^{\text {TM }}$ 802).

Finally, the filtrate was resuspended in water, resulting in aqueous extracts concentrations of $0.5 ; 1.0 ; 1.5 ; 2.0 ; 2.5 ; 5.0$ and $10.0 \%(\mathrm{w} / \mathrm{v})$.

\section{Human blood sample}

Discard blood from FMABC's Laboratory of Clinical Analysis, was used (approval by Ethic Committee number 011/2012), and that material kept in blood test tubes containing sodium citrate or etilenodiamine tetra-acetic acid (EDTA) as anticoagulants (Gonzalez-Covarrubias et al., 2013) and both chelate the calcium ion, one of the most important factors involved in the coagulation cascade that prevents the formation of the blood clot (Borst et al., I2012).

The Human blood sample $(10 \mathrm{~mL})$ were divided in two groups (triplicates) using the coagulation tests and hemogram test: EDTA $(5 \mathrm{~mL})$ (negative control hemogram test) and sodium citrate $(5 \mathrm{~mL})$ plasma (negative control coagulation test).

\section{Coagulation assay}

To determinate the influence of aqueous extracts of Plinia cauliflora (DC.) Kausel in different concentrations on the coagulation activity, were evaluated prothrombin time (PT) and activated partial thromboplastin time (aPTT) by using a hemostasis analyzer (Start ${ }^{\mathrm{TM}}$ - Diagnostica Stago) and the commercial kit 'Thromboplastin Ds in lab hemostasis' for PT and aPTT 'BioTécnica kit'.

For the PT analysis, $500 \mu \mathrm{L}$ of aqueous extract was added in different concentrations to tubes containing $4.5 \mathrm{~mL}$ of blood. The tubes were homogenized and centrifuged at $2500 \mathrm{rpm}$ for 10 minutes. Next, $50 \mu \mathrm{L}$ aliquots of the plasma was taken and incubated at $37^{\circ} \mathrm{C}$ for 60 seconds in the Stago analyzer, to check the clot forming in coagulation assay.

For aPTT tests the same process was used, with the following differences: $50 \mu \mathrm{L}$ of aPTT reagent was added and incubated for 180 seconds at $37^{\circ} \mathrm{C}$, followed by the addition of 50 $\mu \mathrm{L}$ of sodium chloride $\left(\mathrm{CaCl}_{2}\right)$, exhibiting the intrinsic pathway function.

All the data from PT and aPTT using the aqueous extracts were compared to blood and sodium citrate results.

\section{Hemogram}

For the Complete Blood Count (CBC), $500 \mu \mathrm{L}$ from different aqueous extract concentrations in $4.5 \mathrm{~mL}$ of blood was used in a $\mathrm{CBC}$ analyzer (Pentra $\left.{ }^{\mathrm{TM}} 120\right)$ to obtain the red cell blood 
count results, hemoglobin, hematocrit, platelet and platelet distribution width (PDW); these were compared to a solution of blood and EDTA. The manual smear was prepared to evaluate the estimated platelet count. Thin air-dried blood smears were made after thorough mixing of each sample and stained manually with a May-Grünwald Giemsa stain and then examined under light microscopy with a X100 oil-immersion lens.

\section{RESULTS AND DISCUSSION}

The phytochemical screening tests showed that of Plinia cauliflora (DC.) Kausel leaves contained several active compounds (Table 1).

Table 1: Phytochemical composition of Plinia cauliflora (DC.) Kausel leaves.

\begin{tabular}{lc}
\hline Phytochemical & Interference \\
\hline Total phenols & + \\
Tannins & + \\
Flavonoids & + \\
Alkaloids & - \\
Saponins & - \\
\hline
\end{tabular}

Table 3 presents the results from Hemogram for the aqueous extract of Plinia cauliflora (DC.) Kausel leaves, with EDTA used as control.

To complement these findings, normal smears and those with addition of plant extracts were done (Figure 1).
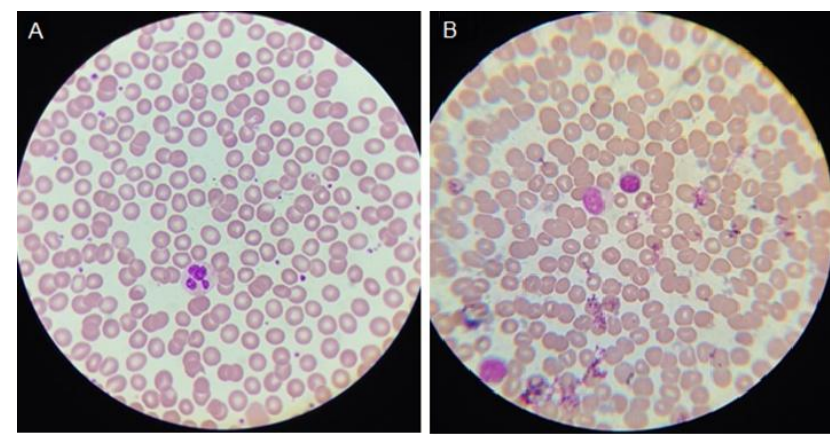

Fig. 1: Blood smears (100x). A) Blood sample untreated. B) Blood sample treated (2.5\% aqueous extract of Plinia cauliflora (DC.) Kausel leaves).

The use of antithrombotic plants could be an alternative to reduce the side effects from pharmaceutical products commonly used in thrombotic-related diseases (Chaves et al., 2010). At first an alcoholic extract was prepared which was more effective solvent for extracting secondary metabolites than aqueous extracts (Chandrasekaran and Venkatesalu, 2004). However, this was removed and the obtained powder was used the aqueous extracts due to better compatibility with blood. In this study, the phytochemical screening showed (Table 1) the presence of polyphenols, especially tannins and flavonoids (flavones, flavanones, isoflavones and chalcones), which were already associated with hemostasis alteration. The antiplatelet activity can be attributed to the increased production of prostacyclin by endothelian cells, and its decreasing aggregation via synthesis of cAMP, and the increased concentration of cAMP, therefore inhibiting the expression of platelet GPIIb/IIIa receptors (Bojić et al., 2011). To show the anticoagulant effect of Plinia cauliflora (DC.) Kausel leaves aqueous extracts, tests were performed in plasma to assess clotting time. PT tests (prothrombine and factors V, VII and X) and aPTT tests (factors VIII, IX, X, XI and XII, prothrombine and fibrinogen) (Sivrikaya et al., I2013) were used to analyze the effects on the extrinsic and intrinsic blood coagulation tenase. In assessing the anticoagulant activity (Table 2) it was found that aqueous extracts of Plinia cauliflora (DC.) Kausel leaves at $0.5 \%$ and $1.0 \%$ concentrations were not tested due to coagulation prior to centrifugation; however, the $1.5 \%$ extract coagulated after centrifugation. These samples were unsuitable for the PT and aPTT tests and the remaining tested concentrations $(2.0 \% ; 2.5 \% ; 5.0 \%$ and $10.0 \%)$ didn't show any coagulation and could not be measured on the analyzer (StartDiagnostica Stago ${ }^{\mathrm{TM}}$ ). On the other hand, conflicting results in the test system didn't make data collection possible, as shown in Table 2 (no clotting forming).

Table 2: Coagulogram results.

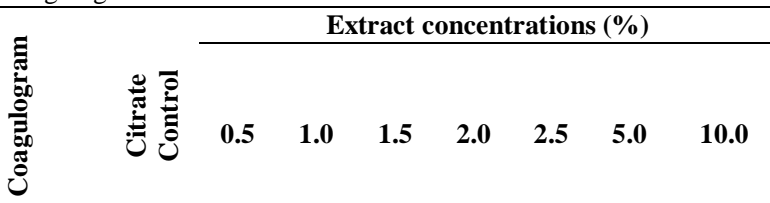

\begin{tabular}{ccccccccc}
\hline PT (seconds) & 16.0 & + & + & + & - & - & - & - \\
aPTT(seconds) & 36.4 & + & + & + & - & - & - & - \\
\hline Legend: (+) clot forming; (-) no clot forming; PT (prothrombim time), aPTT
\end{tabular}
(activated partial thromboplastin time).

Thus, it is possible to suggest that this plant species shows an anticoagulant activity (PT) much higher than that exhibited in leaves aqueous extracts of Enicostemma littorale (22.1 seconds), Acheranthus aspera (10.2 seconds), Abutilon indicum (50.5 seconds) and Tridax procumbens (30.5 seconds) at $20.0 \%$ concentrations (Mahajan and More 2012). However, a folkloric herbal extract, Ankaferd Blood Stopper (ABS), constituted of a standardized mixture of the plants (dried grass extract of Thymus vulgaris, dried leave extracts of Glycyrrhiza glabra, Vitis vinifera, Alpinia officinarum and dried root extract of Urtica dioica) used in Asian Turkey as coagulant effect (Haznedaroglu et al., 2012). The ABS when applied in whole blood, plasma and serum samples, induced very rapid ( $<1 \mathrm{~s})$ protein network formation within concurrent vital erythroid aggregation (red blood cells and activated leukocytes within the whole blood sample as well as within the plasma and serum samples) showing a classical coagulation cascade (Haznedaroglu et al., 2010). Sample hemogram of results showed a significant reduction in platelet concentration, especially at Plinia cauliflora (DC.) Kausel leaves aqueous extracts $2.5 \%$, as displayed in Table 3, while the other parameters seem to be lower, except platelet distribution width (PDW). Since the early results obtained for anticoagulant activity (Table 2), showed a clot forming, the hemogram test was not evaluated. According to Vagdatli et al. (2010), the platelet distribution width (PDW) is a specific marker that reflects its alteration. 
Table 3: Hemogram results.

\begin{tabular}{|c|c|c|c|c|c|}
\hline \multirow{2}{*}{ Hemogram } & \multirow{2}{*}{ EDTA Control } & \multicolumn{4}{|c|}{ Extract concentrations (\%) } \\
\hline & & 2.0 & 2.5 & 5.0 & 10.0 \\
\hline Red cell & $4.6 \times 10^{6}$ & $3.9 \times 10^{6}$ & $3.8 \times 10^{6}$ & $4.0 \times 10^{6}$ & $3.9 \times 10^{6}$ \\
\hline Hemoglobin & $15.8 \mathrm{~g} / \mathrm{dL}$ & $13.4 \mathrm{~g} / \mathrm{dL}$ & $13.3 \mathrm{~g} / \mathrm{dL}$ & $14.3 \mathrm{~g} / \mathrm{dL}$ & $14.3 \mathrm{~g} / \mathrm{dL}$ \\
\hline Hematocrit & $46.6 \%$ & $39.5 \%$ & $38.9 \%$ & $41.5 \%$ & $39.4 \%$ \\
\hline Platelet & $35.60 \times 10^{4}$ & $8.70 \times 10^{4}$ & $7.90 \times 10^{4}$ & $14.40 \times 10^{4}$ & $28.80 \times 10^{4}$ \\
\hline PDW & $12.3 \%$ & $27.8 \%$ & $20.8 \%$ & $23.0 \%$ & $24.0 \%$ \\
\hline
\end{tabular}

Legend: E (plant extract); EDTA (ethylene diamino tetracetic acid); PDW (platelet distribution width).

When associated with the plant extract and blood sample, the PDW was increased, as shown in Table 3. This suggests a reduction in the free platelet count, which is an indication of an increase of heterogeneity (Figure 1). Flavonoids are secondary metabolites associated to platelet activity inhibition, and this action is due to several reasons, such as binding to the membrane surface receptor, modifying its protein structures and even disrupting its physical integrity (Pignatelli et al., I2000; Vilahur and Badimon, 2013); this might explain the absence of these structures in the smears showed in Figure 1B.

\section{CONCLUSION}

It can be suggested that the aqueous extracts of $P$. cauliflora (DC.) Kausel leaves have anticoagulant and antiplatelet activities. The compounds present in these extracts show an important key role in platelet maintenance, nonetheless more investigations are required to identify exactly what flavonoid is involved in that process.

\section{Financial support and sponsorship: Nil.}

Conflict of Interests: There are no conflicts of interest.

\section{REFERENCES}

Aguirre J, Borgeat A. 2013. Drugs for Thromboprophylaxis: Unfractionated Heparin, Low Molecular Weight Heparin, Warfarin, and Fondaparinux. In: LLAU JV. (Ed) Thromboembolism in Orthopedic Surgery, London: Springer, London, England, p. 53-65.

Bates SM, Weitz JI. Coagulation Assays. Circulation, 2005;112: e53-e60.

Bojić M, Debelijak Ž, Tomičić M, Medić-Šarić M, Tomić S. Evaluation of antiaggregatory activity of flavonoid aglyconeseries. Nutr J, $2011 ; 10: 73$.

Borst $\mathrm{O}$ et al. The serum-and glucocorticoid-inducible kinase 1 (SGK1) influences platelet calcium signaling and function by regulation of Orai1 expression in megakaryocytes. Blood, 2012;119: 251-61.

Chandrasekaran M, Venkatesalu V. Antibacterial and antifungal activity of Syzygium jambolanum seeds. J Ethnopharmacol, 2004; 91: 105-108.

Chaves DSA, Costa SS, Almeida AP, Frattani F, Assafim M, Andzingali RB. Metabólitos secundários de origem vegetal: uma fonte potencial de fármacos antitrombóticos. Quim Nova, 2010; 33: 172-180.

Fuentes E, Palomo I. Antiplatelet effects of natural bioactive compounds by multiple targets: Food and drug interactions. J Functional Foods, 2014; 6: 73-81.

Gonzalez-Covarrubias V, Dane A, Hankemeier T, Vreeken R. J. The influence of citrate, EDTA, and heparin anticoagulants to human plasma LC-MS lipidomic profiling. Metabolomics, 2013; 9: 337-348.

Harborne JB 1998. Phytochemical Methods - A Guide to Modern Techniques of Plant Analysis, London: Chapman and Hall, p. 182- 190
Haznedaroglu BZ, Haznedaroglu IC, Walker SL, Bilgili H, Goker H, Kosar A, Aktas A, Captug O, Kurt M, Ozdemir O, Kirazli S, Firat HC. Ultrastructural and morphological analyses of the in vitro and in vivo hemostatic effects of Ankaferd blood stopper. Clin Appl Thromb Hemost 2010;16:446-53.

Haznedaroglu BZ, Beyazit Y, Walker SL, Haznedaroglu IC. Pleiotropic cellular, hemostatic, and biological actions of Ankaferd hemostat. Crit Rev Oncol Hemat , 2012; 83:21-34.

Mahajan R, More D. Evaluation of anticoagulant activity aqueous and ethanolic extracts and their isolated phytochemicals of some medicinal plants. Int J Pharm Pharm Sci, 2012; 4: 498-500.

O'leary KA, Pascual-Tereasa S, Needs PW, Bao YP, O’brien NM, Williamson G. Effect of flavonoids and vitamin $E$ on cyclooxygenase-2 (COX-2) transcription. Mutat Res Fund Mol Mech Mut, 2004; 551: 245-254.

Ostrowski AP, Valentini SA, Pavanelli MF. Atividade anticoagulante do extrato aquoso, hidroetanólico e óleo essencial das folhas de Tropaeolummajus. SaBios, 2014; 9: 46-53.

Pignatelli P, Pulcinelli FM, Celestini A, Lenti L, Ghiselli A, Gazzaniga P, Pandvioli F. The flavonoids quercetin and catechin synergistically inhibit platelet function by antagonizing the intracellular production of hydrogen peroxide. Am J Clin Nutr, 2000; 72:1150-1155.

Poulsen BK, Grove EL And Husted SE. New oral anticoagulants. Drugs, 2012; 72: 1739-1753.

Sivrikaya A, Baran H, Abusoglu S, Ozturk B, Vatansev H, Ali UNLU. Effect of Gender and Age on the Prothrombin Time (PT), Activated Partial Thromboplastin Time (aPTT) Levels and International Normalized Ratio (INR). Int J Mevlana Med Sci, 2013; 1: 27-30.

Souza-Moreira TM, Moreira RRD, Sacramento LVS, Pietro RCL. Histochemical, phytochemical and biological screening of Plinia cauliflora (DC.) Kausel, Myrtaceae, leaves. Braz J Parmacog, 2010;20: 40-53.

Souza-Moreira TM, Severi JÁ, Santos E, Silva VYA, Vilegas W, Salgado HRN, Pietro RCL. Chemical and Antidiarrheal Studies of Plinia cauliflora. J Med Food, 2011; 14: 1590-1596.

Trease GE, Evans WC. 1989. Textbook of Pharmacognosy. $12^{\text {th }}$ Ed. London: Balliere, 310p.

Vagdatli E, Gounari E, Lazaridou E, Katsibourlia E, Tsikopoulou F, Labrianou I. Platelet distribution width: a simple, practical and specific marker of activation of coagulation. Hippokratia, 2010; 14: 28-32.

Versteeg HH, Heemskerk JW, Levi M, Reitsma PH. New fundamentals in hemostasis. Physiol Rev, 2013; 93: 327-358.

Vilahur G, Badimon L. Antiplatelet properties of natural products. Vasc Pharmacol, 2013; 59: 67-75.

WHO - World Health Organization. 2015. Cardiovascular diseases. Available at: http://www.who.int/mediacentre/factsheets/fs317/en/ Acess in 17.03.2016.

\section{How to cite this article:}

Tanelli F, Belardo TG, Peiro CHF, Gama RM, Fonseca FLA, Armando-Junior J. Preliminary Studies on Anticoagulation and Antiplatelet Activities of Plinia cauliflora (Mart.) Kausel Leaves Extract. J App Pharm Sci, 2017; 7 (04): 115-118. 